\title{
Benutzung 2008
}

von Martina Lüll

\begin{tabular}{|c|c|c|c|c|c|c|c|}
\hline \multicolumn{8}{|l|}{ Statistik der Benutzungsbereiche } \\
\hline & 2002 & 2003 & 2004 & 2005 & 2006 & 2007 & 2008 \\
\hline \multicolumn{8}{|l|}{ Allgemeine Angaben zur Benutzung } \\
\hline Aktive Benutzer & 32.619 & 33.597 & 34.206 & 36.005 & 36.936 & 36.331 & 37.076 \\
\hline - davon student. Nutzer & & & & & 19.067 & 18.769 & 19.325 \\
\hline Neue Benutzerausweise & 10.838 & 10.719 & 11.033 & 11.239 & 11.300 & 10.714 & 10.992 \\
\hline Lesesaalbenutzungen insgesamt & 296.620 & 278.866 & 258.632 & 298.622 & 311.721 & 318.602 & 332.828 \\
\hline \multirow[t]{2}{*}{ Öffnungstage } & 284 & 287 & 251 & 294 & 290 & 290 & 292 \\
\hline & & & $+22=273^{*}$ & & & & \\
\hline \multicolumn{8}{|l|}{ Benutzung am Ort insgesamt } \\
\hline Entleihungen & 1.012 .891 & 1.020 .180 & 1.130 .380 & 1.204 .159 & 1.305 .783 & 1.374 .696 & 1.392 .833 \\
\hline Tagesdurchschnitt & 2.071 & 2.031 & 2.308 & 2.357 & 2.603 & 2.732 & 2.790 \\
\hline Vormerkungen & 108.502 & 114.747 & 129.342 & 141.845 & 160.086 & 178.350 & 197.259 \\
\hline Verlängerungen & 382.193 & 394.821 & 461.130 & 483.374 & 525.587 & 559.580 & 555.442 \\
\hline Mahnungen & 65.238 & 62.459 & 72.945 & 74.859 & 83.844 & 82.087 & 94.400 \\
\hline Rückbuchungen & 593.468 & 596.437 & 652.654 & 688.823 & 748.130 & 791.152 & 814.151 \\
\hline \multicolumn{8}{|l|}{ Fernleihe } \\
\hline Aktiver Leihverkehr & 48.338 & 42.234 & 52.450 & 69.508 & 88.625 & 89.534 & 87.509 \\
\hline ohne Verlängerungen & 36.881 & 35.820 & 44.859 & 54.854 & 63.442 & 69.467 & 72.808 \\
\hline Verlängerungen Aktiver Leihverkehr & 11.457 & 6.414 & 7.591 & 14.564 & 25.183 & 20.067 & 14.701 \\
\hline Passiver Leihverkehr & 14.534 & 13.505 & 19.216 & 31.633 & 33.334 & 33.388 & 33.859 \\
\hline
\end{tabular}

Mit knapp über 37.000 aktiven Benutzern und nahezu 1,4 Mio. Entleihungen im Jahr 2008 hat die WLB wiederum eine Nutzungssteigerung um 2\% bzw. 1,3\% im Vergleich zum Vorjahr zu verzeichnen. Durchschnittlich werden 2.790 Medien pro Tag entliehen.

Die Quote der studentischen Benutzerschaft erhöhte sich auf $52 \%$, v.a. Studierende der Universitäten Stuttgart und Tübingen nutzen unsere Bestände und Arbeitsplätze.

Die Intensität der Nutzung lässt sich an der Kennziffer „Vormerkungen“ ablesen. Der Anstieg um knapp 11\% auf fast 200.000 bedeutet, dass jedes vierte Buch, das zurückgebucht wird, nicht mehr ins Magazin zurückgestellt, sondern sofort wieder im Selbstabholerbereich für den nächsten Entleiher bereitgelegt wird.

Die Lesesaalnutzung nahm um 4,5\% zu. Wer allerdings in den vergangenen Wochen entweder im Hauptlesesaal, in den Sonderlesesälen oder auch nur auf der FoyerEbene eine Arbeitsmöglichkeit suchte, hatte mitunter Pech. Restlos alle, auch die versteckten und die zusätzlich ad hoc geschaffenen Arbeitsplätze waren belegt. Glücklich war, wer irgendwo eine freie Steckdose fand. Die junge Nutzergeneration nahm es gelassen und breitete sich zwischen den Regalen auf dem Boden aus. Aber eigentlich ist das ein unhaltbarer Zustand. Die Bibliothek platzt aus allen Nähten. Die Anforderung an den Erweiterungsbau, 2015 insgesamt 475 Arbeitsplätze, v.a. dringend benötigte Gruppenräume, anbieten zu können, ist daher mehr als gerechtfertigt. 
Im Durchschnitt der vergangenen Jahre wurden pro Jahr 10.976 neue Benutzerausweise ausgestellt. Gespannt darf man sein, wie sich die zum Mai 2009 angekündigte Einführung einer Jahresbenutzungsgebühr in Höhe von $30 €$ für den berufstätigen Nutzer auswirken und auch ob sich die Benutzerstruktur insgesamt ändern wird. Unabhängig von statistischen Analysen ist jedoch die entscheidende Frage, zu welchen Ergebnissen die Einführung der Gebühr in einer Gesamtabwägung führen wird. In die Waagschale zu werfen sind die Quote des Benutzerrückgangs, die Bruttoeinnahmen sowie der personelle Mehraufwand für ein aufwendigeres Anmeldeverfahren (jährliche Prüfung im Einzelfall, ob Gebührenbefreiungs- oder Ermäßigungstatbestände greifen). Anfang 2011 werden wir dazu mehr wissen. 